\title{
0 entrelugar do aprendizado escolar de História: uma perspectiva de História Pública
}

The In-Between of School History Learning: A Public History Perspective

Sonia Wanderley*

\section{RESUMO}

Em um contexto marcado pela desconfiança ou mesmo descrédito em relação às explicações oferecidas pela ciência para os problemas contemporâneos, como dar sentido social ao aprendizado histórico escolar? A discussão aqui apresentada tenta entender a potência transformadora desse tipo de aprendizado exatamente pelo entrelugar que ocupa entre a metódica da ciência histórica e o diálogo crítico no tocante aos sentidos de orientação de narrativas históricas produzidas pela cultura histórica. Como um debate didático da História escolar, incorporando noções e conceitos do campo de pesquisa do ensino de História no Brasil e da sociologia de Boaventura dos Santos, o texto constrói a hipótese de que aprender História significa ir ao encontro de uma educação verdadeiramente humanista, função pública do conhecimento histórico.

Palavras-chave: aprendizado escolar de História; didática da História; História Pública.

\section{ABSTRACT}

In a context marked by mistrust or even discredit in relation to the explanations offered by science to contemporary problems, how to give social meaning to historical school learning? The discussion presented here tries to understand its transformative power exactly by the interlacing that historical school learning occupies - between the method of historical science and a critical dialogue that develops with historical narratives produced by historical culture. As a didactic of school History debate, incorporating notions and concepts from the research field of History teaching in Brazil and the sociology of Boaventura dos Santos, this text builds the hypothesis that learning History means meeting a truly humanistic education, public function of historical knowledge.

Keywords: school History learning, didactic History; Public History.

\footnotetext{
* Universidade do Estado do Rio de Janeiro (UERJ), Rio de Janeiro, RJ, Brasil. soniamaiw@gmail. com
} 


\section{CONHECIMENTO HISTÓRICO - ENTRE A CARÊNCIA E A REPULSA}

A procura por explicações históricas nos dias de hoje vem motivando ainda mais os historiadores a refletirem acerca do sentido social de suas pesquisas e atuação. De forma aparentemente contraditória, no Brasil, a eficiência do teor explicativo/interpretativo constituinte da narrativa historiográfica é contestada por diferentes esferas sociais e políticas. A História, enquanto conhecimento que afirma sua participação no campo científico, sofre os efeitos de uma rejeição social em relação à capacidade explicativa das medidas e demandas propostas por organismos científicos. Entrementes, narrativas com teor histórico, produzidas por instâncias sociais variadas, públicas ou privadas, buscam hegemonia na construção de sentido para o estar no tempo. Mesmo a História escolar, com toda interação e diálogo desenvolvidos com outros saberes/narrativas não acadêmicos, sofre com o desgaste social das explicações pautadas por um "estatuto científico", baseadas em uma "metodologia científica".

É bem verdade que, se levado a sério, esse debate em torno da validade da ciência tornar-se-ia sem sentido, haja vista o fato de os próprios cientistas, mesmo nas chamadas ciências "duras", indicarem a dificuldade de se definir "ciência". Segundo o biólogo geneticista brasileiro Freire-Maia, as divergências residiriam em três motivos: o fato de toda e qualquer definição ser incompleta, ou seja, existiria sempre a possibilidade de incluir ou excluir algo; a complexidade mesmo de tal tarefa e, por fim, a falta de acordo entre aqueles que se debruçam em busca dessa resolução (FREIRE-MAIA, 1998, p. 24).

A perspectiva das ciências humanas não é diferente. A história da ciência nos indica o caráter processual e flexível dessa construção, na medida em que um projeto com tais objetivos intenta responder a diferentes questões impostas pelas necessidades e esperanças nas quais as sociedades humanas se encontram mergulhadas, em momentos diversos. Em um determinado instante, explica a filósofa Marilena Chauí, o caminho trilhado pela humanidade em direção ao racionalismo, pelo menos no Ocidente, pode ter levado a um determinismo: o desejo de "eliminar o acaso na natureza, a contingência na história e a fortuna na ética e na política" (1996, p. 22). Porém, hoje em dia, esse tipo de racionalidade é contestado até mesmo pelos cientistas. A tresloucada campanha anticientífica da atualidade perde a referência quando mesmo nas áreas das ciências naturais ou tecnológicas afirma-se a provisoriedade de muitas 
certezas: "A ciência opera com o provável, isto é, com o possível submetido a cálculos" (ibidem).

O presente texto pressupõe as condições citadas e, partindo dessa falta de unanimidade, mesmo de consenso, na definição de ciência, assim como de uma discussão acerca do que seja o conhecimento de senso comum e sua relação com o conhecimento científico (MORAIS, 1998; SANTOS, 2002), tenta compreender como tal contexto vem influenciando a validação social das narrativas produzidas pelo aprendizado histórico escolar.

Vamos considerar as seguintes questões norteadoras: Qual a importância da disciplina escolar história na vida prática de crianças e jovens em idade escolar? Como iluminar o valor social da produção de sentido efetivada pela História escolar diante de um conjunto de narrativas que, constituídas a partir de processos vulgarizadores de sentidos de senso comum, são, mesmo assim, tidas como legítimas por mostrarem-se capazes de instituir identidades, respondendo aos anseios e dúvidas individuais e coletivos de orientação no espaço/tempo? Por fim, qual o diferencial esperado no aprendizado escolar de História?

Nossa hipótese é a de que a construção de respostas para tais questões deve partir do reconhecimento da singularidade da orientação produzida pela História escolar, tendo em vista sua constituição em um território como o da cultura histórica, que transita entre o conhecimento científico e os originários do senso comum. Entendemos que em um momento como esse de pandemia mundial, no qual o excesso de informações reverbera sentidos pautados pelas fake news, negacionistas e simplistas, a disciplina História escolar deve manter um lugar especial na educação formal por desenvolver de uma maneira particular a consciência história ${ }^{1}$ dos alunos, localizando-os no mundo a partir de uma abordagem diferenciada, que muito provavelmente não seria oferecida à maioria dos estudantes fora do caldo cultural produzido na/pela escola.

A argumentação que vamos construir parte da perspectiva de que o aprendizado escolar de História, quando direcionado à função de orientação para a vida prática, portanto, preocupado com o desenvolvimento da competência narrativa histórica, incorpora o significado de História Pública, por ser uma práxis que se estabelece de forma compartilhada, principalmente, entre alunos(as) e professor(a); e por fazer parte da cultura histórica, apresentando, recepcionando e comunicando saberes/narrativas históricas que 
circulam em um ambiente multifacetado por conhecimentos de caráter científico e de senso comum.

\section{CONHECIMENTO CIENTÍFICO, SENSO COMUM E CULTURA HISTÓRICA}

Mas será que o conhecimento baseado no senso comum é tão nocivo assim à orientação de alguém? Conhecimento científico e senso comum são mesmo irreconciliáveis? Essas perguntas, feitas por um mestrando, professor de História na escola básica, a partir da leitura de um artigo que se propunha discutir as especificidades do saber histórico escolar, foi o ponto de partida para esse texto. As questões refletiam angústias de quem não conseguia produzir em sala de aula uma consistente defesa da narrativa de base científica diante "daquelas fundamentadas no senso comum, mas que faziam sentido para o aluno", dizia o meu aluno/professor.

Não é objetivo deste texto apresentar uma discussão sobre definições e significados do conhecimento científico. ${ }^{2} \mathrm{O}$ caminho que escolhemos trilhar para pensar acerca da questão apresentada pelo mestrando foi o de dialogar com o pensamento do sociólogo Boaventura dos Santos que, em diferentes textos, desde meados da década de 1990 (1995, 2006, 2010), vem construindo novas bases para a discussão da relação entre o conhecimento científico e o senso comum.

Pintando com cores político-históricas a sua análise, o sociólogo português relaciona o conflito que se estabelece entre conhecimento científico, tornado verdade absoluta, e senso comum, por ele entendido como sabedoria popular, a uma dominação colonialista que se sobrepôs a outra epistemológica, resultando subalternidade para os saberes locais (2010), semelhante à das áreas ditas periféricas em relação aos países centrais capitalistas. Em síntese, essa é a chave explicativa utilizada por Santos para sugerir uma outra epistemologia, aproximando saberes populares de uma nova proposta de ciência que produziria resultados mais democráticos e inclusivos.

Anteriormente, em obra editada em 1995, Santos discutiu o que denomina a constituição do modelo global de racionalidade científica quando, no século XIX, os estudos sociais assumiam como seus os métodos e técnicas das ciências naturais (SANTOS, 1995, p. 10). Sua crítica incidiu, então, sobre o que 
considerou a instituição de um modelo totalitário estabelecido por essa racionalidade científica aplicada à análise do social.

Corroborando outros tantos estudos, o sociólogo português apontava o momento em que entra em crise o paradigma da racionalidade científica: ainda no início do século passado, quando cientistas buscavam uma compreensão filosófica para suas práticas, indicando que estas não poderiam ser explicadas apenas pela racionalidade do conhecimento científico (SANTOS, 1995, p. 30). Há, como dito, no desenvolvimento dessa argumentação a construção de um paralelo com a contestação tanto político-econômica quanto epistemológica da dominação hegemônica ocidental sobre os países do Sul (SANTOS, 1995; 2006). Nesse contexto, o sociólogo apontava a emergência de um novo "paradigma de um conhecimento prudente para uma vida decente" (SANTOS, 1995, p. 37).

Dois pontos desse novo paradigma são centrais para a discussão aqui desenvolvida: o rompimento da dicotomia entre as ciências naturais e as sociais e o reconhecimento de que existem contribuições recíprocas entre ciência e senso comum. Para Santos, primeiro, não há como ser diferente, haja vista o fato de a ciência atual ser construída dentro de uma sociedade que foi por ela modificada. Dessa maneira, todo conhecimento científico, inclusive o natural, teria sua face social. Da mesma forma, a ciência deveria buscar constituir-se como senso comum, pois as virtudes de ambos contribuiriam para um mundo melhor de todos os seres humanos (idem, p. 37, 55-56).

Em um tempo de incertezas, como o da contemporaneidade, portanto, na leitura proposta por Santos, o estatuto científico, constituído desde o século XIX, assumiria uma flexibilidade. Corroborar com essa perspectiva, entretanto, não significa negar ou negligenciar o papel do conhecimento científico na reflexão sobre as coisas do mundo, em destaque o seu rigor metodológico. A ciência hoje apenas passa a reconhecer a possibilidade de suas verdades serem provisórias e utiliza-se de sua racionalidade para, ao mesmo tempo, sustentar e substituir, quando necessário, tais verdades (FRANCELIN, 2005).

Mas, afinal, como podemos conceituar senso comum? Apesar da polissemia do termo, vamos nos utilizar de Cotrim (2000) para defini-lo como um "vasto conjunto de concepções geralmente aceitas como verdadeiras em determinado meio social”; definição muito próxima daquela construída por Boaventura, como "sabedoria popular". Partimos da premissa de que "os concei- 
tos nascem no cotidiano (ou seja, no âmbito do senso comum) são apropriados pelo meio científico e tornam-se científicos ao romperem com esse cotidiano, com esse senso comum" (idem, s. p.). Isso posto, ficaria estabelecida, a princípio, uma importante oposição entre essa noção e a de conhecimento científico.

Vamos apresentar rapidamente as ideias de dois filósofos que ajudaram a construir essa oposição e depois tentaremos estabelecer uma relação com a proposta desenvolvida por Santos acerca da constituição de um novo sentido para senso comum. Um dos filósofos essenciais na problematização da diferenciação entre essas duas categorias é o francês Gaston Bachelard. Para ele, especialista em filosofia da ciência, a diferença constrói-se como uma dicotomia entre opinião, uma forma de pensamento superficial e simples, e ciência, com seu desenvolvimento epistemológico como critério de conhecimento:

A ciência, tanto por sua necessidade de coroamento como por princípio, opõe-se absolutamente à opinião. Se, em determinada questão, ela legitimar a opinião, é por motivos diversos daqueles que dão origem à opinião; de modo que a opinião está, de direito, sempre errada. A opinião pensa mal; não pensa: traduz necessidades em conhecimentos. Ao designar os objetos pela utilidade, ela se impede de conhecê-los. Não se pode basear nada na opinião: antes de tudo, é preciso destruí-la. Ela é o primeiro obstáculo a ser superado. Não basta, por exemplo, corrigi-la em determinados pontos, mantendo, como uma espécie de moral provisória, um conhecimento vulgar provisório. O espírito científico proíbe que tenhamos uma opinião sobre questões que não compreendemos, sobre questões que não sabemos formular com clareza. (BACHELARD, 1996, p. 18)

Na perspectiva materialista histórica, o pensador em cuja obra o conceito de senso comum torna-se fundamental é o italiano Antonio Gramsci. Muitos de seus intérpretes o consideram como mais um nome dentre os que estabelecem uma ruptura intransponível entre ciência e senso comum. Nos textos em que relaciona hegemonia, reforma moral e intelectual, Gramsci interpreta senso comum como "uma visão de mundo difundida nas classes subalternas de forma desordenada e assistemática". Para Gramsci, seriam dois os elementos constitutivos fundamentais do pensamento do tipo senso comum - religião e folclore. A partir deles, afirma, constituir-se-ia uma "visão ocasional e incoerente, resultado da herança histórica cultural desagregada e popularizada" (apud MARI e GRADE, 2012, p. 120). 
O filósofo marxista brasileiro Leandro Konder corrobora a ideia de que a obra de Gramsci aponta para horizontes "inevitavelmente muito limitados", no que se refere à capacidade reflexiva do conhecimento de senso comum, aproximando-o, por ser "difuso e incoerente", restrito à uma compreensão imediata e superficial, ao sentido pejorativo de ideologia. No entanto, afirma Konder, o filósofo italiano deixa aberta também a interpretação de que essa noção "possuía um caroço de 'bom senso', a partir do qual poderia se desenvolver o espírito crítico" (GRAMSCI apud KONDER, 2002, s. p.) Nesse sentido, diz, apesar do sentido de postura passiva que Gramsci imprime ao conceito de senso comum, antevê-se a possibilidade de sua transmudação em "bom senso" a partir da disposição crítica dos indivíduos refletirem por conta própria, tendo em vista os instrumentos de que disporiam para tal. Konder nos lembra que a ciência também não escapa da possibilidade de aproximação com o sentido negativo da ideologia, pois não pode fugir à sua condição de produto da História:

A ciência é um conhecimento que se expande, que se aprofunda e se revê, se corrige, continuamente. [Mas] ela também é histórica, não pode pretender situar-se acima da história, não pode pretender escapar às marcas que o fluxo da história, a cada momento, imprime nas suas construções. Por isso, não é razoável tentar promover uma contraposição rígida entre ciência e ideologia. (Ibidem, s. p.)

Percebe-se que as reflexões acerca da diferenciação entre ciência e senso comum tendem a abandonar o campo de oposição absoluta. Uma mostra dessa interpretação é vista em um recente texto do sociólogo e educador Ivan Dourado (2018), no qual ele se propõe dialogar com tais leituras de oposição tendo em vista superá-las por meio de um "mapeamento conceitual mais amplo de senso comum". O autor nos lembra que tais polarizações dicotômicas se estabelecem historicamente como um tipo de "construção discursiva" e servem para legitimar a capacidade explicativa de um dos pares da oposição, tal como aconteceu historicamente entre fé e razão, Igreja e Universidade etc.

É no sentido de combater perspectivas niilistas ou messiânicas que podem resultar de construções narrativas desse teor que advogamos uma leitura atenta da proposta apresentada por Santos acerca da constituição de uma nova epistemologia para pensarmos a relação entre senso comum e conhecimento científico sem, com isso, confundirmos um no/com outro. 
Santos reconhece a necessidade histórica da ciência ao efetivar o que Bachelard denomina "primeira ruptura epistemológica", ou seja, definir de forma singular seu campo de produção de conhecimento e pesquisa científica. Entretanto, admite a fragilidade dessa ruptura no que se refere às ciências sociais (SANTOS, 1995, p. 35). Eu incluiria nessa discussão a História, entendida aqui como ciência social. A apropriação de Gadamer por Santos parece-nos um caminho pertinente para o debate que se faz urgente nos dias de hoje, tendo em vista romper com maniqueísmos e perspectivas simplistas da questão.

Os preconceitos são constitutivos do nosso ser e da nossa historicidade e, por isso, não podem ser levianamente considerados cegos, infundados e negativos. São eles que nos capacitam a agir e nos abrem a experiência e, por isso, a compreensão de nosso estar no mundo não pode de nenhum jeito dispensá-los. (SANTOS apud DOURADO, 2018, p. 225)

Aproximando-se do sentido atribuído ao "caroço do bom senso" de Gramsci, essa percepção nos propõe pensar que senso comum também produz conhecimento, mesmo que "mistificado" e "mistificador". Reconhecendo suas "virtualidades" para enriquecer "nossa relação com o mundo", o autor ilumina a possibilidade de uma "dimensão utópica e libertadora que pode ser ampliada através do diálogo com o conhecimento científico” (SANTOS, 1995, p. 56).

Nesse ponto desviamos nossa escrita para o campo da ciência histórica. Admitindo a necessidade do diálogo crítico entre o conhecimento histórico científico e as diferentes narratividades carregadas de sentido histórico que se multiplicam no mundo contemporâneo, iniciou-se um movimento reflexivo que deu densidade à noção de cultura histórica (RÜSEN, 1994; SÁNCHEZ MARCOS, 2010). Com este conceito, teóricos da História tentam explicar a importância que a memória histórica vem ganhando no espaço público desde o final do século XX e, cremos, de certa forma, confessando a necessidade de o conhecimento historiográfico participar do diálogo proposto acima por Santos.

O que nos interessa dessa discussão é perceber que o protagonismo social adquirido pela História nos dias de hoje não tem necessariamente a ver com os escritos dos historiadores acadêmicos (profissionais) ou, até mesmo, com manuais histórico-didáticos, mas com narrativas produzidas por "um conjunto de lugares de memória coletiva" que integram não necessariamente as funções da produção historiográfica ou do ensino-aprendizagem, mas "do entre- 
tenimento, da legitimação, da crítica, da distração, da ilustração e outras maneiras de memorar"3 (RÜSEN, 1994, s. p.). Além disso, o conceito abarca para além do que é elaborado por diferentes agentes sociais, muitas vezes concorrentes e por diversos meios, para abranger a difusão, as representações que legitimam os sentidos constituídos e a recepção dessas narrativas.

Segundo Sánchez Marcos:

A noção de cultura histórica emerge, com uma tensão teórica e implicações filosóficas inegáveis, como um conceito heurístico e interpretativo para entender e investigar como são criadas e transformadas certas imagens do passado relativamente coerentes e socialmente operativas, nas quais se objetiva e articula a consciência histórica de uma comunidade humana. (SÁNCHEZ MARCOS, 2010, p. 1)

Dessa maneira, cultura histórica se definiria por ser um "sistema sócio-comunicativo de interpretação, objetivação e uso público do passado”. Um "processo dinâmico de diálgo social", marcado pela negociação entre "interpretações distintas do passado" e forjado por "múltiplas narrativas e diferentes abordagens, que lutam para se impor socialmente" (ibidem).

Em nossa leitura, o aprendizado escolar de História pode objetivar de maneira potente a capacidade de análise e transformação social proposta pelo conceito de cultura histórica. Com seus objetivos singulares, a História escolar focaliza formas diferentes de interpretar, objetivar e comunicar a relação que os homens estabelecem com o passado em um dado presente. E, na medida em que se constitui como narratividade, forjada a partir de uma epistemologia singular que considera a historiografia, mas também estabelece um diálogo crítico com narrativas históricas outras e resgata a função pública do conhecimento histórico.

Quando a comunicação do saber histórico escolar se operacionaliza dessa forma - dialogando criticamente com saberes e narratividades oriundos do senso comum, porém pensados como "reativamente coerentes e socialmente operativos" - adquire o status de uma operação historiográfica, prospecta um tipo de conhecimento/ação que pode assumir o caráter transformador pensado por Santos e acolher a perspectiva humanista proposta por Rüsen para a didática da História: “[...] uma Didática da História Humanista que permita aos sujeitos terem acesso aos princípios de uma aprendizagem histórica emancipadora e que os levem ao autoconhecimento a partir do reconhecimento do 
outro, no processo de formação da consciência histórica" (FRONZA, SCHMIDT, 2015, p. 6).

\section{HISTÓRIA ESCOLAR COMO HISTÓRIA PÚBLICA ${ }^{4}$}

O que aqui sublinhamos é a centralidade cada vez maior de uma "multiplicidade de práticas cotidianas" (JULIA, 2001) levadas para a sala de aula, ${ }^{5}$ muitas vezes ancoradas em narrativas que disputam com a narrativa historiográfica, e que não podem ser desconsideradas quando da constituição de sentido para o aprendizado de História na vida prática dos alunos. Diversos elementos da cultura histórica contemporânea permeiam o sentido de verdade construído pelos aprendizes e nos cabe perguntar como a aprendizado histórico escolar, constituído em diálogo com a metódica racional científica historiográfica, pode contribuir para dar maior complexidade ao significado/importância que esses alunos lhe atribuem.

Em outras palavras, gostaríamos de refletir como a epistemologia da História relaciona-se ao aprendizado escolar e a outros tipos de aprendizados que pululam na cultura histórica e são carreados para dentro da sala de aula, passando a fazer parte da cultura escolar e fixando condições de partida diferenciadas pela interação desenvolvida na sala de aula. Um aprendizado que, sem perder a capacidade transformadora da racionalidade historiográfica, visa à vida prática e produz sujeitos orientados para agir no complexo mundo real que existe para além dos muros escolares (RÜSEN, 2010a, p. 99).

Ora, essa construção dialética e dialógica, resultante da interação de consciências históricas diversas, é o lócus no qual pode se concretizar o caráter de História Hública da prática da História escolar. É como prática e não apenas a partir de uma epistemologia diferenciada que a História escolar se define como um campo singular. Ou seja, estamos aqui defendendo que a especificidade da História escolar só se concretiza como práxis quando, pensada a partir de uma didática própria, possibilita a capacidade de assumir a dimensão utópica e libertadora anunciada por Santos (1995) e a perspectiva humanista proposta por Rüsen:

Isso diz respeito à responsabilidade histórica com os compromissos que podem levar o homem a se tornar humano, no processo de luta pelo reconhecimento da 
dignidade do outro. Compromisso que não se refere somente em manter as conquistas humanistas já realizadas, mas democratizá-las para aqueles que, desde séculos, ainda sofrem como vítimas de processos desumanizadores e etnocêntricos. (FRONZA; SCHMIDT, 2015, p. 9)

Cabe aqui um parêntese para explicar como estamos entendendo o estudo da especificidade da História escolar a partir de uma didática própria. A relação que se estabelece entre a disciplina escolar História e a produção de conhecimento histórico já foi por demais discutida em diferentes campos da ciência da Educação e, mesmo que em menor escala, há algumas décadas, também pela Teoria da História e pela Historiografia. Cabe aqui referenciar que partimos da premissa de que, sem prejuízo do reconhecimento da singularidade axiológica e epistemológica da História, resultado da pesquisa historiográfica, e da História, disciplina ensinada na escola básica, esta última deveria ser parte importante dos estudos históricos.

Essa certeza vem da convicção de que as perguntas que devem ser feitas quando se pensa o ensino-aprendizagem de História não se restringem ao como ou o que ensinar, mas, perpassam a essência de "como se pensa a história, [portanto, das formas de aprendizado], quais são as origens da história na natureza humana, [o sentido de orientação que estas conduzem], e quais são os seus usos para a vida humana [suas relações com a vida prática]" (RÜSEN, 2010, p. 24).

Tais questões se apresentam como uma reflexão didática da História, partindo do princípio de que tal forma de ver a Didática a entende como uma disciplina que pode "desempenhar um papel importante na escrita e na compreensão histórica”. Por essa compreensão, a Didática da História amplia seus objetos de estudo para além da sala de aula, se propondo analisar "todas as formas e funções do raciocínio e conhecimento histórico na vida cotidiana, prática” (RÜSEN, 2010, p. 24 e 32)

Para Cerri (2005), essa perspectiva de pensar a Didática da História a coloca como uma "teoria geral do aprendizado histórico" que investiga "a circulação social do conhecimento histórico" (2010). Seu objeto, portanto, transcenderia o espaço da sala de aula, na medida em que se pensa esse aprendizado como "a habilidade de se orientar na vida e de formar uma identidade histórica coerente e estável” (RÜSEN, 2010, p. 40). Em síntese, se a enxergar- 
mos como uma disciplina singular, seu campo de atuação abrangeria o aprendizado escolar de História, os usos públicos da História e mesmo a ciência histórica propriamente (como um campo de autorreflexão) (SADDI, 2012).

Nossa reflexão nesse artigo, embora se direcione para o primeiro campo apresentado, qual seja, o da aprendizagem escolar de História, não pode desprender-se do sentido apresentado para a didática da História. Explicando melhor, compreender que o aprendizado histórico não se restringe ao espaço escolar e que, mesmo este, estará sempre impregnado das formas diferenciadas de orientação temporal que os homens carregam para a sala de aula - o sentido humano inato de orientar-se no tempo para estabelecer identidade(s) e compreender seu lugar no mundo.

O objetivo é discutir que, em uma conjuntura como a que vivemos nos dias atuais, principalmente no Brasil, de revisionismos negacionistas e posicionamentos político-sociais irracionalistas e anticientíficos, o aprendizado escolar de História potencializa-se como uma instância que, fazendo dialogar narratividades diversas presentes no ambiente escolar, a partir dos pressupostos da ciência histórica, e considerando as singularidades da cultura histórica escolar, facilita o desenvolvimento de identidades históricas coerentes e estáveis.

Assim, também o professor atua como um historiador público quando é capaz de fazer dialogar historiografia e outros conhecimentos/narrativas que produzem sentidos para o estar no tempo na realização de um aprendizado de história significativo. O professor/historiador público entende o conhecimento histórico escolar como uma construção compartilhada para a qual contribuem narratividades que se entrecruzam muitas vezes em oposição, em conflito, mas sempre como partes importantes da busca por orientação e identidade, seja individual ou social.

Esse professor tem a correta compreensão de seu papel, e o de sua expertise como profissional de História, na apreensão/interpretação das “ideias tácitas" trazidas pelos alunos. Do mesmo modo, ele assume sua faceta de cientista social, pois deve ser capaz de mobilizar a epistemologia histórica e outros conhecimentos necessários à tarefa de ensinar História na educação básica para gerar inquietações/reflexões que certamente estarão além daquelas trazidas incialmente por seus alunos para a sala de aula. Essas últimas são, muitas vezes, frutos do senso comum e, embora devam ser ultrapassadas, são legítimas, posto que até então os vinha capacitando a agir, a ler o mundo. Não po- 
dem ser dispensadas e delas deve partir a ação educativa para um aprendizado significativo.

Se "aprender" for entendido, fundamental e genericamente, como processo no qual as experiências e as competências são refletidas interpretativamente, esse conceito de aprendizado diz respeito ao que se discute aqui: a contribuição da ciência histórica para o desenvolvimento daquelas competências da consciência histórica que são necessárias para resolver problemas práticos de orientação com o auxílio do saber histórico. (RÜSEN, 2010a, p. 94)

Apontamos a importância e o compromisso do aprendizado histórico escolar na/com a mobilização mais complexa da consciência histórica. Compreendendo que isso não ocorre se não se considerar como fundamental o diálogo com a cultura histórica na qual os aprendizes e os docentes estão inseridos, portanto, sua visibilidade como História Pública.

Com isso, também nos identificamos com a ideia de que a definição de História Pública não se restringe tão somente à possibilidade carreada pela ação do historiador de buscar um público mais amplo, mas passa, necessariamente, por considerar na operação mesma de produção do conhecimento histórico - seja historiográfico ou histórico escolar, como é o nosso caso aqui - qual a relação que esse conhecimento mantém com um público que constitui sentidos para o estar no tempo a partir de instâncias tão variadas.

É desta forma que, como dizem Penna e Silva (2016), a aula de História pode ser vista como uma operação historiográfica. Os autores, em diálogo com o clássico texto de Certeau (2002), A escrita da História, reconhecem o potencial da noção operação historiográfica, por articular lugar, práticas sociais e um texto, ${ }^{6}$ mas consideram, a partir da perspectiva da História Pública, "outras operações historiográficas realizadas pelos profissionais de história” (PENNA, SILVA, 2016, p. 198). Assim sendo, o aprendizado realizado, da forma como enunciado, na sala de aula, seria também fruto de uma operação historiográfica. Operação esta que articula de maneira singular um lugar social (diríamos um entrelugar), práticas sociais geridas a partir da especificidade da cultura escolar, e um texto, ou narrativa constituidora de sentido para o estar no tempo.

Estamos, da mesma forma, referenciando a importância do professor na mediação ${ }^{7}$ para a construção colaborativa que caracteriza esse aprendizado. A ideia de História Pública que propomos relaciona-se também a um tipo 
de prática docente que define este profissional como intelectual público aquele que sublinha o sentido público da constituição do conhecimento histórico escolar:

[...] o estudo da história está mudando sua ênfase do ensino e aprendizado num sentido mais restrito para um campo mais amplo com objetivos ainda pouco claramente definidos. Ainda é uma questão aberta se a ênfase na vida pública da didática da história terá um eco positivo. Mas deveria ficar claro que, desde que o público não pode digerir a produção de uma disciplina profissional altamente especializada da história profissional sem mediação, existe a necessidade definitiva de pessoal treinado e disposto a cumprir esta mediação. O que deveria ser evidente é que as habilidades normais adquiridas pelo historiador profissional não são suficientes para a execução dessa mediação. (RÜSEN, 2010, p. 33)

\section{APRENDIZADO ESCOLAR DE HISTÓRIA E VIDA PRÁTICA}

Chegamos à última questão norteadora do presente texto - o papel da História na produção de um tipo de aprendizado transformador, democrático e humanista proposto por Santos e Rüsen, respectivamente, diante de um mundo singularizado pelo ceticismo e descrença na validade e eficiência do conhecimento científico. E, no que se refere mais especificamente ao ensino de História no Brasil, o retorno com toda a força, no campo das políticas públicas, da perspectiva de análise que pensa a aprendizagem como um processo apenas cognitivo de aquisição de conhecimento, assim como o forte retorno da ideia de uma neutralidade da práxis educativa. De novo resgatamos a essência daquilo que consideramos ser o trunfo da História escolar diante desse quadro - sua singularidade e capacidade na mediação das diferentes narrativas históricas que coexistem e disputam espaço hegemônico na cultura histórica contemporânea na qual estão mergulhados os sujeitos que fazem parte das culturas escolares.

Dizer que a aprendizagem de história e as narrativas que a explicitam fazem parte da cultura histórica e, portanto, refletem as disputas que existem no mundo extra escolar pode parecer uma obviedade, mas, muitas vezes, é uma questão não levada em consideração na reflexão que abarca as variáveis que influenciam tal processo: 
É trivial e conhecido de todos que na aprendizagem da história muitos outros fatores estão em jogo, mas, isso sempre é esquecido rapidamente. Muito mais difícil é a pergunta se o não-apenas-cognitivo deve, pode ou até mesmo precisa ser objetivo expresso da aula de história - ou justamente não! [...] Há muitos que rejeitam toda a influência intencional, por exemplo, nas emoções ou imaginação. Mas, não é tão simples. [...] Faz sentido seguir a concepção de "cultivo das emoções" e de "civilização do partidarismo", ou seja, expressar e pôr em discussão os próprios sentimentos da forma mais aberta possível (mas não obsessivamente), em vez de passar por cima deles como uma espécie de tabu e assim aceitar que eles sejam negados timidamente ou absolutizados autoritariamente. (BORRIES, 2018, p. 25-26)

Em síntese, podemos inferir que o autor corrobora a perspectiva de que a aprendizagem escolar de História tem a função de auxiliar o aluno/aprendiz em sua orientação no tempo, forjando identidade(s), e que o processo em que essa orientação se constitui não é desprovido do "não-apenas-cognitivo". Muito antes da etapa de escolarização, o indivíduo "ao existir, ao decidir, ao agir [...] necessita constituir e colocar em funcionamento sua consciência histórica" (CERRI, 2011, p. 112). Em diferentes espaços sociais, portanto, ele forma conceitos e preconceitos, conhecimentos de senso comum carreados para a produção de sentidos realizada durante o aprendizado escolar de História.

É na ambiência do senso comum, disputa de significados que se estabelecem no cotidiano; do conhecimento científico, constituído pela metódica que caracteriza a formação profissional do professor de História; e da cultura escolar, para onde são carreados esses e outros saberes da cultura histórica, que se estabelece a singularidade do aprendizado histórico escolar. Para que esse aprendizado consiga, hoje em dia, diferenciar-se necessariamente das partes que o constituem, de forma a atender ao objetivo didático histórico de desenvolvimento integral do aprendiz, ele necessita caracterizar-se como um processo aberto a dar "ênfase na vida pública da didática da história”, como nos ensina Rüsen (2010), e constituir-se como uma práxis marcada pela necessidade de produzir sentido acerca do "cultivo das emoções" e da "civilização do partidarismo", tão sabiamente apontada por Borries (2018), e assumir "a humanidade como base no princípio da dignidade humana", propugnado por Rüsen (2015). 


\section{EM BUSCA DE UM SENTIDO (?)}

Retornamos a este texto, depois de um silêncio de mais de 30 dias, em um momento que já é por muitos considerado uma virada civilizatória para a humanidade. O mundo se encontra paralisado pela pandemia da Covid-19. A perplexidade causada por seus efeitos, apesar da resistência de alguns interesses, levou-nos forçadamente a considerar uma parada como imprescindível. Todos em casa, em quarentena! O vaivém naturalizado de nossas atividades foi abruptamente ceifado. A necessidade de repensar hábitos, necessidades e prioridades fez-se urgente. Essa situação paralisou também nossa escrita. Outras inquietações surgiram como mais importantes, com maior significado. Agora, no momento em que tentamos retornar ao texto, as considerações acerca do que estamos vivendo não podem ser invisibilizadas no caminho tortuoso da escrita acadêmica. Elas aderem à argumentação como o vírus à célula humana. $\mathrm{E}$ as narrativas históricas ${ }^{8}$ produzidas, direta ou indiretamente, pelos agentes sociais que estão vivendo a turbulência desse momento transformam-se em fontes para nossas alegações finais.

Qual a importância de se discutir o papel do aprendizado escolar de História em um momento no qual a escola, como território de aprendizado e socialização, torna-se um espaço impossível de convivência? Por outro lado, em um tempo no qual os interesses sempre atuantes que transformam educação em mercadoria ecoam com mais força diante da impotência de tantas vozes aferradas ao tradicionalismo da resistência que identifica no espaço físico e na presença física, diria mais, corporal, o aspecto mais significativo da possibilidade do fazer escolar?

Não caberia nos objetivos desse artigo discutir com profundidade o caldeirão de problemas que o distanciamento social provocou nas relações socioafetivas/cognitivas estabelecidas como base para o aprendizado escolar no Brasil, principalmente na escola pública. Ainda não temos certeza se poderemos voltar à mesma escola que deixamos ao terminar o ano letivo de 2019, quando tudo isso terminar. Mas, cremos que se possa utilizar muitos dos significados que vêm servindo para orientar a vida social nesse momento de incerteza para tornar mais clara a importância de um aprendizado de História 
escolar que se organize como prática de História Pública, fundamentada na Didática da História.

Como viemos discutindo até aqui, o ensino de História na escola alcança verdadeiramente o aprendizado quando constrói sentido sobre a experiência do tempo, reflete questões que estão produzindo sentidos para a cultura histórica na qual aprendizes e professores estão mergulhados e resulta em narrativas que a problematiza. Dizendo de outra forma, só aprendemos História quando recorreremos à experiência individual e social para interpretar o passado, de forma a agir no presente e orientar futuros possíveis.

Desta forma, o aprendizado histórico - como uma elaboração compartilhada dos sujeitos que compõem a cultura histórica - transcende os aprendizes presentes na ação educativa, o espaço social no qual é produzido, em nosso caso, a escola, e seus objetivos mais formativos disciplinares. Ainda mais no contexto atual de pandemia e negacionismos, a faceta da História escolar como prática de História Pública tem que ser fortalecida.

O âmago do processo educativo está em aceitar esta responsabilidade pelo mundo, mesmo que estejamos insatisfeitos com ele no momento presente. A educação passa por inserir estes jovens no mundo e garantir que eles assumam este compromisso pela sua continuidade, caso contrário sua existência está em risco. (PENNA e SILVA, 2016, p. 201)

Garantir que estudantes/aprendizes da História escolar, principalmente aqueles oriundos da escola pública, responsabilizem-se pelo mundo que receberam e que ajudam ou ajudarão a construir significa pensar, como afirma Borries (2018), que ensinar História é muito mais do que considerar apenas aspectos cognitivos. Se queremos que o aprendizado escolar de História ocupe um papel de destaque no processo educativo acima enunciado, precisamos, como diz o historiador alemão, romper com essa "grande e perigosa ilusão" e, sem deixar de dialogar com os sentidos estabelecidos nesse mundo torto que temos, romper com os simplismos de senso comum e, no entrelugar em que ele se encontra, moldar o "caroço de bom senso" gramsciano a partir de alguns princípios fundamentais de uma educação humanista: a "proibição de subjugar", o "imperativo da controvérsia", a "chance de articulação identitária" e a “orientação por métodos” (BORRIES, 2018, p. 27). 


\section{REFERÊNCIAS}

BACHELARD, G. A formação do espírito científico. Rio de Janeiro: Contraponto, 1996.

BORRIES, Bodo Von. Jovens e Consciência histórica. Schmidt, Maria Aparecida; Fronza, Marcelo; Nechi, Lucas Pydd (Orgs.). Curitiba: W.A. Editores, 2018.

CERRI, L.F. Ensino de história e consciência histórica - implicações didáticas de uma discussão contemporânea. Rio de Janeiro: Ed. FGV, 2011.

CHAUÍ, Marilena. Contingência e necessidade. In: NOVAES, Adauto (Org.). A crise da razão. São Paulo: Companhia das Letras, 1996.

DOURADO, Ivan P. Senso comum e Ciência: uma análise hermenêutica e epistemológica do senso comum de oposição. Educar em Revista. Curitiba, v. 34, n. 70, jul./ ago. 2018, p. 213-229.

FRANCELIN, Marivalde M. Ciência, senso comum e revoluções científicas: ressonâncias e paradoxos. Ciência da Informação, [S.l.], v. 33, n. 3, jun. 2005.

FREIRE-MAIA, Newton. A ciência por dentro. Rio de Janeiro: Vozes, 1998.

FRONZA, Marcelo; SCHMIDT, Maria Auxiliadora. Contribuições de Jörn Rüsen para a didática da história na perspectiva do humanismo. In: RÜSEN, Jörn. Humanismo e didática da História. (organização e tradução de Maria Auxiliadora Schmidt [et al.]). Curitiba: W.A. Editores, 2015.

JULIA, Dominique. A cultura escolar como objeto histórico. Revista Brasileira de Educação. v.1, nº 1, p. 9-43, jan./jun. 2001.

KONDER, Leandro. A questão da ideologia em Gramsci. In: Gramsci e o Brasil. Disponível em: https://www.acessa.com/gramsci/?id=298\&page=visualizar. Acesso em: 22 nov. 2019.

MARI, C. L.; GRADE, M. O senso comum e a educação em Antonio Gramsci: dimensões singulares da práxis. In: Mari, Cezar Luiz De; Coelho, Edgar Pereira, Santos; Geraldo Marcio Alves. (Orgs.). Educação e formação humana: múltiplos olhares sobre a práxis educativa. 1 ed. Curitiba: CRV, 2012.

MONTEIRO, Ana Maria. Professores: entre saberes e práticas. Revista Educação \& Realidade. $\mathrm{n}^{\circ}$ 74, p. 121-142, abril/2001.

MONTEIRO, Ana Maria; PENNA, Fernando de A. Ensino de História: saberes em lugar de fronteira. Revista Educação \& Realidade. v. 36. n 1, p. 191-211, jan./abr. 2011.

MORAIS, Regis de. Filosofia da ciência e da tecnologia. 5. ed. São Paulo: Papirus, 1988.

PENNA, Fernando de Araújo; SILVA, Renata da C. A. da. Operações que tornam a história pública: A responsabilidade pelo mundo e o ensino de história. In: ALMEIDA, Juniele Rabêlo de; MAUAD, Ana Maria; SANTHIAGO, Ricardo (Orgs.). 
História pública no Brasil. Sentidos e itinerários. São Paulo: Letra e Voz, 2016. p. 195-205.

RÜSEN, Jörn. ¿Qué es la cultura histórica? Reflexiones sobre una nueva manera de abordar la historia. 1994. Disponível em: http://www.culturahistorica.es/rusen/ cultura_historica.pdf. Acesso em: 10 nov. 2019.

RÜSEN, Jörn. Didática da História: Passado, presente e perspectivas a partir do caso alemão. Revista Práxis Educativa, Ponta-Grossa-PR, v.1, n 1, 15 jul./dez. 2006.

RÜSEN, Jörn. Jörn Rüsen e o ensino de História (organizadores: Maria Auxiliadora Schmidt, Isabel Barca, Estevão de Rezende Martins). Curitiba: Ed. UFPR, 2010.

RÜSEN, Jörn. História viva: teoria da história: formas e funções do conhecimento histórico. Brasília: Editora Universidade de Brasília, 2010a.

RÜSEN, Jörn. Humanismo e Didática da História. Trad. e org.: SCHMIDT, Maria Auxiliadora; BARCA, Isabel; FRONZA, Marcelo; NECHI, Lucas Pydd. Curitiba: Ed. UFRP, 2015.

SÁNCHEZ MARCOS, Fernando. Cultura histórica. 2009. Disponível em: http://www. culturahistorica.es/cultura_historica.html. Acesso em: 25 mar. 2020.

SANTOS, Boaventura. S. Um discurso sobre as ciências. Lisboa: Afrontamento, 1995.

SANTOS, Boaventura. A gramática do tempo: para uma nova cultura política. São Paulo: Cortez, 2006

SANTOS, Boaventura. Para além do pensamento abissal: das linhas globais a uma ecologia de saberes. Revista Crítica de Ciências Sociais [online], n. 78, 2007.

SFORNI, Marta Sueli de Faria. Aprendizagem e desenvolvimento: o papel da mediação. Disponível em: gestaoescolar.diaadia.pr.gov.br/arquivos/File/sem_pedagogica/fev_2010/aprendizagem_desenvolvimento_papel_mediacao.pdf. Acesso em: 14 out. 2020.

\section{NOTAS}

${ }^{1}$ Concordando com Borries que a categoria consciência histórica é "realmente um pouco abstrata e desajeitada", mas, ao mesmo tempo, compreendendo sua potencialidade explicativa, principalmente no que se refere aos objetivos de se ensinar História, vamos aqui nos preocupar menos em defini-la e mais em caracterizar as dimensões que a estruturam: cultura histórica, identidade histórica e competência histórica (BORRIES, 2018, p. 19-20).

${ }^{2}$ De forma geral vamos considerar que estamos definindo conhecimento científico como aquele produzido na academia, ou instituições congêneres, e que persigam as bases teórico-metodológicas do campo científico.

${ }^{3}$ Todas as traduções do presente no texto são de responsabilidade da autora. 
${ }^{4}$ A discussão desenvolvida neste item em parte foi sustentada no texto apresentado ao $30^{\circ}$ Simpósio Nacional da ANPUH, ocorrido em julho de 2019, na UFPE, Recife.

${ }^{5}$ Quando Julia (2001) fala em cultura escolar, não se refere apenas aos elementos presentes nas normas e preceitos formais, mas, principalmente, à "multiplicidade das práticas cotidianas" aí presentes, reveladoras de tensões e contradições e que são de fundamental importância no vislumbre dos tipos de consciência histórica que se apresentam na sociedade e, por conseguinte, imprescindíveis na discussão acerca da qualidade social que se quer para a escola e, em nossa discussão, para o ensino de História.

${ }^{6}$ Por analogia, vamos identificar o que os autores denominam texto àquilo que aqui definimos como narrativa, haja vista verificar-se em ambas as construções a preocupação com a produção de sentido.

${ }^{7}$ Quando definimos o papel do professor nesse processo como um mediador, não queremos simplificar essa posição como a de alguém que, por ser mais experiente, está preparado para ajudar a criança, menos capacitada, a concretizar um desenvolvimento que não conseguiria atingir sozinha. Embora esta perspectiva, uma interpretação realizada a partir das ideias de Vygotsky, não esteja incorreta, ela reduz a função da mediação às relações interpessoais. Nossa perspectiva parte da premissa de que a função mediadora que se espera do professor ultrapassa à relação sujeito-sujeito, incluindo o objeto desta relação, qual seja, o conhecimento. "Em outras palavras, é somente na relação entre sujeito-conhecimento-sujeito que a mediação se torna um conceito fundamental ao desenvolvimento humano" (SFORNI, 2010, s.p.).

${ }^{8}$ Aqui compreendida como produtora de sentido em si e não como discurso ou representação. Para a Didática da História (fundamentada na teoria da consciência histórica) o que dá sentido de orientação temporal, ou seja, dá forma concreta, visibilidade à consciência histórica dos sujeitos, são as narrativas históricas.

Artigo recebido em 31 de agosto de 2020. Aprovado em 8 de outubro de 2020. 